\title{
Türkiye Türkçesi Ağızlarında "Domates, Kedi, Patates" Kelimeleri ve Bir Kelime Haritası Denemesi
}

\author{
An Exploration of a Word Map: The Words "Tomato, Cat and Potato" in the \\ Turkey Turkish Dialects
}

\begin{abstract}
Safiye GENÇ ${ }^{*}$
Ali Cín ${ }^{* *}$

Öz: Modern anlamda ağız çalışmalarının Türkiye'de Avrupa'dan yaklaşık altmış yıl geç başlaması, var olan malzemenin zamanında derlenip kayıt altına alınarak üzerinde çalışılmaması, dil atlaslarının ve kelime haritalarının hazırlanamamasındaki en önemli etkenlerdendir. Türk Dil Kurumu'nun 1932-1934 yıllarını kapsayan birinci ve 1952-1959 yıllarını kapsayan ikinci derleme çalışmaları, bu alanda o zaman için Türkiye Türkçesiyle yapılmış en kapsamlı çalışmalar olmakla birlikte, çalışmanın devamı getirilememiş ve en önemlisi de elde edilen malzeme dil atlasına dönüştürülememiştir. Türkiye'de kelime ve ağız atlaslarının ihmal edilmesi, bu çalışmaların öneminin yetirince anlaşılamamasından da kaynaklanmaktadır. Söz konusu çalışmamızda, Türkiye Türkçesi ağızlarında farklı ses birimlerle kullanılan "domates", "patates" ve "kedi" kelimeleri üzerinde durulmuş ve bu kelimeler, geçtiği yerlerle birlikte Türkiye haritası üzerinde gösterilerek bir kelime haritası çalışması yapılmıştır. Çalışmada kullanılan malzeme, Türkiye'de Halk Ăgzından Derleme Sözlüğü, 12 cilt (TDK Yay. Ankara 1993) adlı çalışmaya dayanmaktadır. Haritalarda bazı bölgelerden yeterince veri bulunmadığı görülmüştür. Bu bölgelere ait veriler, söz konusu bölgelerde yaşayan veya önceden yaşamış olan kişilere danışılarak tamamlanmaya çalışılmıştır.
\end{abstract}

Anahtar sözcükler: Kelime Haritası, Türkiye Türkçesi Ağıları, Domates, Patates, Kedi

\begin{abstract}
The reasons that retarded the preparing of the language atlases in Turkey are; that dialect studies in a modern sense began nearly sixty years later than in Europe, and the existing material was not compiled, recorded and worked upon at the correct time. The first study, covering the years 1932-1934 and the second, covering the years 1952-1959 by the Turkish Language Association (TDK) are the most extensive studies conducted in Turkey on Turkish, but subsequently, these studies could not be enlarged upon, and, most importantly, a language atlas of this material could not be prepared. The reason why this field of study has been neglected for a long time was because not much importance was given to language atlases. In this study the three words "domates" (tomato), "patates" (potato) and "kedi" (cat) are investigated, which occur in different forms in Turkish dialects. These words are shown with their places of use on a map of Turkey, in the attempt undertaken at a study to form a word map. The material employed was based upon the, Türkiye'de Halk A ğzından Derleme Sözlüğ̈̈, 12 Volumes (TDK Publishing, Ankara 1993). It was seen that data related to the used words in this study has been insufficiently collected from some regions. An attempt has been made to complete this missing data through consulting the local people still living in those regions and those who used to live in those regions.
\end{abstract}

Keywords: Word Map, Turkey Turkish Dialects, Tomatoes, Potatoes, Cat

\footnotetext{
*Yrd. Doç. Dr., Akdeniz Üni., Edebiyat Fakültesi, Alman Dili ve Edebiyatı Bölümü, Antalya. safiyegenc@akdeniz.edu.tr

*** Doç. Dr., Akdeniz Üni., Edebiyat Fakültesi, Türk Dili ve Edebiyatı Bölümü, Antalya. alicin@akdeniz.edu.tr Çalışmamızın haritalama aşamasındaki katkılarından dolayı, değerli dostumuz Adnan GENÇ'e teşekkürlerimizi sunarız.
} 
Dil haritaları, bir dilin bir coğrafyadaki lehçesine ait kelimelerin dağılım bilgisi yanında, dolaylı olarak konuşucuların hayat görüşleri, kültürel kimlikleri, yaşam tarzları ve tarihleriyle ilgili bilgileri de verir. Dünyadaki ağız atlaslarının neler ve kimler tarafından nasıl yapıldığına kısaca bakmakta yarar var. Bu alandaki ilk çalışmalar Almanlar tarafından yapılmıştır. Dünyanın ilk geniş çaplı dil atlasını Alman Georg Wenker (1852-1911) hazırlamıştır. Wenker, 1888-89 yılları arasında, "Sprachatlas des Deutschen Reiches" (Tk. Alman Imparatorluğunun Dil Atlası) çalışmaları esnasında, Alman İmparatorluğunu kapsayacak şekilde bir bütün oluşturan 3 ana harita oluşturmuştur. Bu parçalar Kuzeybatı, Kuzeydoğu ve Güneybatı olmak üzere 50x60 cm boyutunda ve 1/1.000.000 ölçekli haritalardır (Niebaum \& Macha 2014, 68). Günümüze kadar basılı olarak yayımlanmamış olan Alman Dil Atlası'nın tüm materyali Marburg Üniversitesi, Alman Dil Haritası Araştırma Merkezi'nde bulunmaktadır.

Wenker'den önce tek tük ağız haritaları derleme ağız çalışmalarına ek olarak oluşturulmuştu. Bunlar daha çok ağızların coğrafi sınırlarını göstermeyi amaçlıyorlardı. Örneğin, 1819'da Stalder'in "Schweizer Dialektologie" (Tk. Ísveç A ̌̆ız Bilimi) ve 1821'de Schmeller'in "Bayerische Grammatik" (Tk. Baverya Dilbilgisi) eserleri ağız haritaları içermektedir (Mitzka 1952, 7). Wenker başlangıçta Aşağı Ren Bölgesi'nin ağızlarını incelemek istemiştir. Bunun için 1876 yılında Ren Bölgesinin kuzeyindeki yerleşim bölgelerinde görev yapan öğretmenlere standart Almancada yazılmış 42 cümleden oluşan anket gönderir ve cümleleri kendi bölgelerinde konuşulan ağızlara çevirmelerini ister. 1877'de öğretmenlerden gelen geri bildirimlere dayanarak "Sprachkarte der Rheinprovinz nördlich der Mosel" (Tk. Ren Bölgesi'nin Mozel Nehri'nin Kuzeyi Dil Haritası) yazısını yayımlar ve 1878 'de yine bu materyalden yola çıkarak aynı isimli bir dil atlas1 hazırlar (Niebaum \& Macha 2014, 64).

Wenker, 1880'lerden itibaren tüm Alman İmparatorluğu'nu kapsayacak atlası planlamaya başlar. Ren Bölgesi'nin materyaline ek olarak Orta ve Kuzey Alman İmparatorluğu'ndan gelen veriler, ki bunlar yine öğretmenlere gönderilen 40 'ar cümleden oluşan listelerin geri bildirimleridir, 1881'de Alman Dil Atlası'nın Orta ve Kuzey Almanya kısmının taranmasını ve haritalarının oluşturulmasını sağlar. "Sprachatlas von Nord- und Mitteldeutschland" (Tk. Orta ve Kuzey Almanya Dil Atlası) için Wenker, 30.000 yerleşim bölgesinden gelen veriyi değerlendirip oluşturduğu renklendirilmiş dil haritalarına, kendisi şekil vermiş ve haritaların çizimlerini yapmıştır (Mitzka 1952, 9). 1887'den itibaren Almanya'nın Güney'i de çalışmaya dâhil edilir ve yine aynı veri toplama ve haritada işleme yöntemi kullanılır. 1888' de nihayet tüm imparatorluğun verileri derlenmiş ve değerlendirilmiş olur ve Wenker'in Alman Imparatorluğu'nun Dil Atlası, 3 ana parçadan oluşan biçimiyle tamamlanır.

Wenker'in yerine Marburg Dil Haritası çalışmalarının başına geçen Ferdinand Wrede (1863-1934) ve 1933 sonrasında Walther Mitzka (1888-1976) projeyi tüm Almanca konuşulan bölgelere yayar ve harita çizimlerine devam ederler (Mitzka 1952, 10). Tamamlayıcı çalışmalar sonucunda, Alman Imparatorluğunun Dil Atlası'nın temelinde yaklaşı 53.000 yerleşim bölgesinden toplanan veri vardır (Mitzka 1939, 110). Bu çalışmanın 128 haritadan oluşan bir kısmı 1927 ve 1956 yılları arasında yayımlanır. Tüm Atlas'ın içerdiği harita sayısı ise 1668'dir (Niebaum \& Macha 2014, 74).

Wenker'in çalışması baştan beri Almancanın ses ve yapısına yönelik bir dil coğrafyası çalışmasıdır. Wenker, öğretmenlere cümlelerini gönderirken sesleri inceleme düşüncesi ile yola çıkmıştır (Mitzka 1938, 40). Alman Imparatorluğu'nun Dil Atlası çalışmasında az sayıda kelime haritası bulunsa da, bunlar aslında bir yan ürün olarak düşünülebilir. Hedef çalışma, kelime haritası çizmeye yönelik planlanmamıştır. Çalışmaları Alman Dil Atlası'na neredeyse paralel olarak başlatılmış olan Fransız Dil Atlası (Atlas Linguistique de la France) ise hem ses hem de 
kelime haritası olarak tasarlanmış ve veriler buna göre toplanmıştır. Wenker'in haritalarının oldukça sık dokunmuş olması, Alman Atlası'nda geçen kelimeler üzerine ileriye dönük verimli çalışmaları mümkün kılmıştır. Sıklık açısından Fransız Dil Atlası'nda bir yerleşim bölgesi, Alman Dil Atlası'nda 100 yerleşim bölgesine denk gelmektedir (Mitzka 1938, 41). Bu özelliği ile Wenker, Dil Atlası'nın içerdiği kelime haritaları tüm Alman İmparatorluğu'nu kapsayan dağılımı ile bu alanda yapılmış en ayrıntılı kelime haritalarıdır.

Almanya'daki kelime haritası çalışmalarının öncüsü olan Bernhard Martin, 1921 yılında Alman Kelime Coğrafyası için verilerin toplamasına başlar. Martin geri bildirimlere dayanarak 1924 ve 1934 yılları arasında 13 kavrama ait kelime haritası yayımlar (Barth 1972, 126; Niebaum \& Macha 2014, 71). Asıl geniş çaplı kelime haritası çalışması Mitzka tarafindan Marburg Alman Dil Haritası Merkezi çatısı altında Alman Kelime Haritası projesi ile başlatılır. 1938 tarihinde başlayan proje 1980 yılında tamamlanır. Bu çalışma Wenker'in dil haritasını kelime açısından tamamlayıcı bir çalışma olarak düşünülmüş ve planlanmıştır. 1939'dan itibaren o zamanki Alman İmparatorluğunun okulu bulunan tüm yerleşim bölgelerine ve İkinci Dünya Savaşı döneminde de Alman İmparatorluğu'nun dışında bulunan Almanca konuşulan bölgelere, İsviçre hariç, soru fişleri gönderilir. $\mathrm{Bu}$ fişler, eşya ve eylem bildiren kelimeler içermektedir ve öğretmenlere "Bunlara sizde ne ad verilir?" diye sorulur (Mitzka 1939, 110). Bu yolla 1942 'de 48381 okuldan veri elde edilmiş olur (Wiegand \& Harras 1971, 7). İsviçre'deki Almanca konuşulan bölgelerin eksik verileri, daha önce İsviçre'de yapılmış kelime derleme çalışmaları ile giderilir. 1951 yılında Alman Kelime Atlası'nın ilk cildi çıkar. 1942'den itibaren verilerin değerlendirilmesi başlamış olsa da, savaş ortamı yayımı geciktirmiştir. 1978'de yayımlanan 21. cilt ve 1980 'de yer dizini ve ek haritalar içeren 22. cilt ile Alman Kelime Haritası tamamlanmış olur (Niebaum \& Macha 2014, 72).

Dil atlası ile ilgili önemli diğer bir çalışmayı da, Fransızlar yapmıştır. Fransız Dil Atlası'yla ilgili ilk çalışmalar J. Gilliéron ile E. Edmont'a aittir. Fransız bilim adamları, Alman bilim adamlarının çalışmalarına göre farklı bir metot uygulamışlardır. J. Gilliéron, Wenker gibi kırk bini geçkin bir yerleşim biriminden ziyade 639 yer seçmiştir. Wenker, malzemesini soru cümleleri üzerinden toplarken, Gilliéron, hem ağızlardaki söz varlığı hem de kısa cümleler üzerinden malzemeyi toplamıştır. 1903 yılında Gilliéron ve Edmont 1903 yılında Fransız Dil Atlası'nın ilk elli haritasını yayımlamışlardır (Buluç 1946, 176, 177, 178). Dil atlası ile ilgili İtalyanlar'ın ve Ruslar'ın da önemli çalışmalarının olduğu bilinmektedir.

Her ne kadar Türkiye Türkçesi ağızları atlası çalışmaları çok yavaş ilerlese de, modern Türklük dünyasında bu alanda bazı çalışmaların yapıldığı bilinmektedir. Örneğin SSCB'nin 1917-1967 yılları arasında, Azerbaycan, Tatar, Türkmen ve Çuvaş Türkçesin ağız atlasları hazırlanmıştır (Boz 2008, 160). Türkiye Türkçesinin gerek ağız atlası, gerekse kelime haritası bugüne değin maalesef yapılamamış, yapılanlarda geniş kapsamlı olmayan haritalardır. Türkiye'de ağızların haritalaştırılması konusundaki ilk çalışmalardan biri, Leyla Karahan, Anadolu A ğızlarının Sinıflandırılması adlı çalışmadır. Karahan çalışmasının sonunda ses, şekil ve cümle bilgisi hususiyetlerini göz önünde bulundurarak 28 harita yayımlamıştır (Karahan 1996, 205-232). Ahmet Buran'ın Doğu ve Güneydoğu Anadolu'nun Dil Atlası adlı çalışması, bölgede Türkçeden başka Kürtçe, Arapça, Süryanice, Ermenice, Çerkezce gibi dillerin konuşulduğunu ancak ortak anlaşma dilinin, günlük iletişim dilinin Türkçe olduğunu gösteren önemli bir dil atlası çalışmasıdır (Buran 2009). Genel olarak söz konusu zikrettiğimiz bu çalışmaların dışında birçok ağız çalışmasının içerisinde ya da genellikle sonunda belirli sayılarda hazırlanmış haritaları da görüyoruz. Bunlardan bazıları şunlardır: Efrasiyap Gemalmaz, Erzurum İli Ağızları adlı çalışmasında sonunda 1'i söz konusu derleme verilerinin nerelerden toplandığını 
gösteren harita, 2'si ağız gruplarıyla alakalı, 3'ü ek, 1'i ses, birisi kelime haritası olmak üzere (köy kelimesi) 8 harita sunmuştur (Gemalmaz 1995, 385-399). Faruk Yıldırım, Adana ve Osmaniye ağızlarını konu alan çalışmasında 2'si leksik, 7'si ek, 1'i de fiil olmak üzere toplam 10 kelime yayımlamıştır (Yıldırım 2006, 34, 35, 36, 222, 226, 249, 269, 282, 308, 311). Söz konusu ağız çalışmalarıyla ilgili daha geni bilgi için bakınız (Boz 2008, 163).

Türkiye' de, gramatikal ölçütlerle hazırlanan dil haritaları, sayıca leksik olarak hazırlanan dil haritalarından daha fazladır. Leksik ölçütleri esas alan dil haritalarından bazıları şunlardır: Konuyla ilgili bilinen ilk çalışma Ahmet Caferoğlu'na aittir. Caferoğlu, üç bölgeyi temsilen [(Marmara/İstanbul, Çanakkale); (Akdeniz/İzmir, Antalya, Mersin, İskenderun); Karadeniz/ Trabzon, Samsun)] 8 yerleşim merkezi esas alınmıştır. (Cafereoğlu 1960, 111; 1960, 1) Caferoğlu'nun söz konusu çalışmasıyla ilgili herhangi bir harita çalışmasına ulaşamadık. Özcan Başkan, Türkiye'deki köy adları üzerine yapmış olduğu bir deneme çalışmada 1970'li yıllarda sayısı kırk bin civarında olan köy ve şehir adını tarayarak konak, höyük, hisar, kale kelimeleriyle oluşturulan yer adlarıyla ilgili olarak 4 harita yayımlamıştır (Başkan 237, 248-251). Konumuzla ilgili Japon bilim adamı Tooru Haysi'nin iki leksik çalışması vardır. Birincisi Rize, Trabzon, Giresun, Ordu, Samsun bölgelerini kapsayan yengeç ve patates kelimelerinin dağılımını harita ile gösterdiği çalışma, ikincisi ise, Bolu'da manda, hindi, pazar günü, yayla evi, yüzük parmağl, ekilmemiş tarla kavramlarının bölgedeki dağılımını harita ile gösterir. Yine bu konuda Leyla Karahan, 2013 yılında yapmış olduğu çalışmada biri Anadolu ağızlarının sinıflandırılmasından oluşan ve biri de apar-, patates, manda, ayakkabı ve çocuk kelimelerinin haritaları olmak üzere 6 harita yayımlamıştır (Karahan 2013, 10-12). Görüldüğü üzere, kelime haritası çalışmaları da oldukça azdır.

Kelime haritası çalışmamızda, domates, kedi ve patates kelimelerini seçmezinin sebebi, söz konusu kelimelerin Türkiye coğrafyasında birden fazla karşılığının olması ve tanınırlılı̆̆ının yüksek olmasıdır.

Patates, domates ve kedi kelimeleri, haritaya döküldüğünde bazı bölgelerde temsil edilmedikleri görülmüştür. Yani Derleme Sözlügü'nde buralarla ilgili veri bulunmamaktadır. Bu bölgeleri tamamlamak için burada yaşayan ya da daha önce burada yaşamış kişilere başvurarak eksik olan bölgelerle ilgili veri toplanmıştır. Bu yeni veriler incelendiğinde bazı adlandırmaların Derleme Sözlüğ̈̈'nde olanlarla ses ve şekil itibariyle benzerlik gösterdiğini (frenk/Karaman...), bazılarının ise sözlükte yer almadığı görülmüştür. (fireng/Urfa...) Çalışmada, Derleme Sözlüğ̈̈̈'nde yer almayan dolayısıyla veri bulunmayan bölgeler için müstakil ağız çalışmalarından da yararlanılmıştır (Caferoğlu 1960; Ercilasun 1983; Gemalmaz 1995; Gülseren 2000; Yıldırım 2006; Öztürk 2009; Akar 20013).

\section{Patates}

Almanca'daki Kartoffel kelimesi, İtalyanca tartufo kelimesinden gelmektedir. Tartufo aslinda yer elması demektir, ama patatesle benzerliğinden dolayı her ikisine de tartufo denmiştir. 18. yüzyılın başlarında Alman diline kartoffel şekliyle giren kelime, buradan kuzey ve Doğu Avrupa'ya benzer şekillerde yayılmıştır (Grimm 1971, 11/244). Örneğin, Danca tartuffel, Lehçe ve Rusça'da kartofel, Litvanca kartupelis.

Patatesle ilgili bilgileri, son dönem Osmanlı Türkçesi sözlükleri üzerinden de takip edebiliyoruz. Ahmet Vefik Paşa, kelimeyi patata şeklinde verip patatese sehven yer elması denildiğini, Amerikan kökü, tatlı nevine de badata denildiğini ve Afrika'dan geldiğini ifade eder (Vefik Paşa 2000, 309). Toven, kelimenin patates veya patata biçiminde kullanıldığını ve "Maruf bir nevi nebat ki Amerika-yı cenubiden 1534 sene-yi miladisinde Avrupa'ya nakledilmişsir" 
şeklinde açıklar (Toven 2004, 591). Şemsettin Sami ise, patatesin "patate", Amarika'dan çıkmış maruf yer elması nevi ki, mevadd-1 mugaziyyeden olmakla, buğday olmayan şimal cihetlerinde ekmek yerini tutar. (Sami 1316, 339). Türkçe Sözlük patatesin Rumca pata'tes kelimesinden geldiğini ve patatesin "patlıcangillerden, yaprakları ve sürgünleri acı bir bitki ve bu bitkinin toprak altında oluşan, nişastası çok, yenilebilen yumruları olan bitki" olarak tanımlar (Komisyon 2011, 1898).

Halk arasında patates için sıkça kullanılan diğer bir kelime olan kumpir kelimesi de Türkçe Sözlük'te Bulgarca olarak gösterilip, ilk anlam olarak "özel firında pişirilen iri patatesin içine peynir, misir, bezelye vb. malzeme konularak yapılan yiyecek" ikinci anlam olarak da, halk dilinde patates şeklinde açıklanmıştır (Komisyon 2011, 1525). Batıda 18. yüzyılın ortalarından sonra, yer elmasına benzerliğinden dolayı Ren bölgesinde patatese, grundbirne (grund+ birne) yer armudu denmiştir. Fransızcaya grúmbîre şeklinde geçen bu kelime günümüzdeki kumpirin öncüsüdür. (Grimm 1971, 9/762) Türkiye Türkçesi ağızlarına kumpir kelimesi, Slav dilleri üzerinden girmiştir (Bläsing 2008, 55,56). Patates kelimesi için yapılan leksik haritalardan birini Hayashi, Rize, Trabzon, Giresun, Ordu ve Samsun'u kapsayan bir alanda yapmıştır (Hayashi 1984). Diğer bir çalışma, Uwe Bläsing'in patates için kullanılan kumpir kelimesinin ve patatesin diğer söyleş biçimi olan gosdil ve hozmür kelimelerinin yayılış alanını haritalamıştır (Bläsing 2008, 49, 67). Patatesle ilgili son leksik çalışmayı da, patatesin diğer söyleniş biçimlerini Türkiye Türkçesi ağızlarındaki durumunu fonetik ölçütlerle gruplandırarak L. Karahan yapmıştır (Karahan 2013, 10).

Söz konusu bu bilgilerden sonra, Türkiye Türkçesi ağızlarında tespit etmiş olduğumuz patatesin diğer adlandırmalarını, kelimelerin kullanım sıklığı ve fonetik ölçütleri göz önünde bulundurarak gruplandıracağız.

1- gardof/gardop/gardopu/gardubu/garduf/ gardul/garput/gartol/girtüp/gortul/ hartap/ hartına/ kaltur/ kardeh/ kardof/ kardoğ/ kardu/ karduğ/ karnup/ kartal/ kartil/ karto/ kartof/ kartofil/ kartofin/ kartol/ kartolin/ karton/ kartop/ kartopi/ kartopili/ kartopu/ kartul/ katut/ kerto/ kertol/ kortal/ kortol/gordoş

$\mathrm{Bu}$ grupta yer alan kelimeler Almanca kartofell kelimesinden gelip Türkiye Türkçesi ağızlarında fonetik hadiselere bağlı olarak birçok patates adlandırmasını görüyoruz. Coğrafî olarak Almanca ile Türkçe arasındaki ilişkiyi güney Slav dilleri teşkil etmektedir (Bläsing 2008, 55).

2- gompil/ gompir/ gompül/ gompür/ gömpil/ gömpül/ gumpil/ gumpir/ gumpur/ gumpür/ gümbür/ gümpil/ gümpir/ gümpür/ hompur/ honpur/ höngül/ humpur/ kampir/ komper/ kompir/ kompur/ konpil/ kumbil/ kumbur/ kumbür/ kumpil/ kumpir/ kumpiri/ kumpur/ kumpül/ kunpir/ kübül/ kümpür/alamangumpili

Türkiye Türkçesi ağızlarında patatesin farklı adlandırılmasındaki önemli kelimelerden biridir.

3- pata/ patalak/ patana/ patat/ patata/ patatez/ patatis/ patatiz/ pate/ pahe/ patediz/ patele/ patelek/ pates/ patet/ patetis/ patıko/ pati/ patik/ patika/ patike/ patitis/ pattes/ pattik/ pattiz/ petete/ pitana/ pitat/ pitata/ pitina/ pitana/ potat/ potuk/ battis/baduka

4- gostil/ gosdil/ gostül/gösdül/ göstül/ kastil/ kastul/ kostil

5- hazmur/ hormuz/ hozmur/hözmür/ hüzmün/ kozmur

6- yerelma/yer elmasl/yerelmast/yermasi

Yer elması şeklindeki adlandırma büyük bir ihtimalle, Farsçadaki patates için kullanılan sibzemini (sib+zemini) kelimesinden gelmektedir. Diğer bir açılamada, bu grupta yer alan 
patates adlandırmalarının, yer elması olarak bilinen bitkiye benzetilerek yapılmış olmasıdır. (DS/2736-2738).

7- sev/ sevkabinerdl: Yüksekova-Hakkari

8- banadora/ mendura: Ereğli/Konya (DS, II, 514)

9- domatça/ tomatça: Çayıralan, Boğazlıyan-Yozgat (DS, IV, 1550, 3954)

10- yer yumurtası / makfali: Pazar/Artvin

Yer yumurtası biçimindeki patatesin adlandırması, haritada geçen diğer bir adlandırma olan makfali ile bağlantılıdır. Makfali Lazca'daki dixamarkvali (dixa + markvali) "yer yumurtası" kelimesinden gelmektedir. (http://lazuri.com/lazuri_ceviri/index.php)

11- apotz: Posof- Kars (DS, I, 289)

12- gucur: Kemaliye- Erzincan (DS, VII, 2187)

13- longur: Rumeli göçmenleri, Trabzon, Rize (DS, IX, 3086)

14- marsili: Burdur (DS, IX, 3130)

Marsili kelimesi, Fransa'nın meşhur şehri Marsilya ile ilişkilendirilir. 1908-1920'lu yıllarda Marsilya'dan hastalıksız patates tohumları getirilmiştir (Bläsing 2008, 83). Muhtemelen bölge ekim için pilot bölge olarak kullanılmıştır.

15- mirgll: Manisa/Kırkağaç (DS, IX, 3186)

16- pünpürün: Ulukışla- Niğde (DS, IX, 3494)

17- tenbilik: Kartal-İstanbul (DS, X, 3877)

18- ülübe: Karapınar-Konya (S, XI, 4064)

Derleme Sözlüğ̈̈'nde yer almayan patatesle ilgili kelimeler şunlardır: mendura: Samandağ1-Hatay; sev/ sevkabınerdı: Yüksekova-Hakkari; makfali: Pazar/Artvin battis: Aksaray.

Patates kelimesi haritası için bkz. Harita-3.

\section{Domates}

Meksika'dan 16. yüzyılda Avrupa'ya gelen domates kelimesi, Meksika dilinde tomatl biçiminde olup Fransızca ve İspanyolcaya tomate şeklinde girer. Başlangıçta pomme d'amour "aşk elması" adı verilen domates, 19. yüzyılın ortalarında tomate biçiminde kullanılmaya başlanmıștır (Grimm 1971, 21/677). Türkiye Türkçesinde kullanılan domates kelimesinin sonundaki /-tes/ sesi ise Yunancadaki çokluk şeklinden gelmektedir. Domates (kavata), Osmanlı mutfağına 17. yüzyılda giren ve önceleri sadece yeşil olarak tüketilen bir sebzeydi. 1884'te basılan MelceütTabbahin adlı eserde, içine domates konularak yapılan sekiz yemek tarifi bulunmaktadır. (Samanc1 2008, 205). Yine sözlüklerimiz üzerinden domates kelimesi takip ettiğimizde, Vefik Paşa, dometese (domates /tÔせ W): Frenk patlıcanı, türleri için sarı salkım, düz domates, acı domates karşılıklarını verip kavata kelimesine bakılabileceğini belirterek (Vefik Paşa 2000, 122). kavata içinde "patlıcan, acı domates, üzüm domates gibi maruf kırmızı meyve" anlamlarını verir (Vefik Paşa 2000, 221). Sami, dometesin Fransızca'dan geldiğini tomate (domates /"ÔلUا் veya (tÔ W(i) "içi pek sulu ve mayhoşça olmakla gerek tazesi ve gerek şişelerde hifz olunmuş, suyu veya ezmesi ve pestili yemeğe lezzet vermek için kullanılıp âdeten mutfağın havayic-i zaruresi hükmüne geçmiş olan bir sebz ki, Amerika'dan gelme olup enva-1 kesiresi vardır: kırmızı tomate, salkım tomate" şeklinde açıklamıştır (Sami 1316, 910). Toven ise, dometesi "yemeklere lezzet veren kırmızı bir sebze" olarak açıklar (Toven 2004, 154). Türkçe Sözlük ise domates kelimesini, (Lycopersion esculentum) "Patlıcangillerden, yaprakları tüylü, çiçekleri salkım durumunda, vitamince zengin bir bitki; Bu bitkinin yenilen kırmızı veya yeşil ürünü" biçiminde 
açılar (Komisyon 2011, 702).

Türkiye Türkçesi ağızlarında kullanılan banadura, manadura... gibi biçimler, Türkçeye İtalyanca (pomidoro/pomodoro) üzerinden geçmiçtir. Vefik Paşa, patlıcan kelimesini açıklarken Fariside batingan şeklinde geçtiğini, kelimenin aslının Hinçe olmasının muhtemel olduğunu belirttikten sonra patlıcan için "frenk patlıcanı, dometes" denildiğini belirtir (Vefik Paşa 2000, 310). Domates kelimesi Farsça'da kûçe-frengi, tamatam "domates" (Kanar 1988,112), Arapça'da, tomatım "domates" Misır lehçesinde ise, kutata "domates" (Mutçalı 1995, 529, 735) şeklinde geçmektedir. Vefik Paşanın verdiği kavata kelimesi ile Arapçanın Mısır lehçesinde kullanılan kutata kelimesi arasında bir ilişki olmalı.

Türkiye Türkçesi ağızlarında tespit ettiğimiz domatesin diğer adlandırmalarını şöyle gruplandırabiliriz:

1- damates/ domadiz/ domante/ domas/ domat/ domata/ domate/ domatez/ domatis/ domatiz/ domet/ dumates/ tamates/ tamatis/ tamatos/ tamtes/ tanatis/ temetos/ toma/ tomalta/ tomas/ tomat/ tomata/ tomate/ tomates/tomati/ tomatis/ tomete/ tomta:

$\mathrm{Bu}$ grupta yer alan ve çeşitli fonetik sebeplerle yirmiden fazla adlandırması bulunan kelime, Yunanca dometiz kelimesine dayanmaktadır.

2- baladural bamador/ banada/ banadaral banader/ banadoral banadorel banadur/ banadural banatural bandural benedoral benedural bonadural mamador/ manadural manator/ panadora/ panadura:

Bu kelime grubunda yer alan kelimelerin aslı İtalyanca pomodoro/pomidoro (Tietse ,1999, 274) kelimesine dayanmaktadır.

3- albadılcan/ badılcan/ badımcan/ badırcan/baldırcan/ bırmızı badımcan/delibadılcan/ girmızı badilcan/ hambalcan/ hambaldırcan/ patlican/ sarl badılcan/ sarl balcan/ sarlpatlican/bacan/ bacane/ bacan-l sor/bacansor/bacansorh/ balcan/ balcon/ balcun:

$\mathrm{Bu}$ grupta yer alan domatesle ilgili adlandırmalar, dilimize Farsça üzerinden geçmiştir. Vefik Paşa, kelimenin aslını Hintçe olduğunu, Fariside batingan biçiminde kullanıldığını belirtir. Paşa'nın verdiği en ilginç bilgi ise patlıcan kelimesinin domates anlamında kullanıldığını belirtmesidir (Vefik Paşa 2000). Her iki bitkinin patlıcangiller ailesinden olması dolayısıyla böyle bir durum ortaya çıkmış olabilir.

Bacan kelimesi de yine batingan kelimesiyle ilgilidir. Tulum, kelimenin "bādlicān, bādincān, bādingān, bāzincān" şekillerini de vermiştir (Tulum 2011, 1444). Bu gurupta yer alan bācan-sorh'lu biçimler ise batingan'dan gelen bācan ile Farsça kızarmış anlamındaki sorh (bācan-sorh) kelimesinden oluşmaktadır.

5- ferenk/fireng/firıngi/firek/firenk/firenk patlicanl/firingi/ frek/frenk/ frek elmasl/frenk patlicanl/fringi:

Frenk, kelimesi Türkçe Sözlük'te Farsça olarak gösterilip, Anglosakson, Cermen veya Latin ırklarından biri olan kimse olarak anlamlandırılmıştır (Komisyon 2005,717). Tulum, Meninski'nin Thesaurus'unu dikkate alarak frenk kelimesine "Frenk, Frenk vilayeti" anlamının yanı sira "Taliyan, İtalus, İtalia" anlamınını da vermiştir (Tulum 2011, 730). Dolayısıyla adlandırma da buradan gelmektedir.

6- kırmızımamye/ mamya/ mamye/ maniya/ maniyce/ maniye/ manya/ maye/ menize/ mülye:

$\mathrm{Bu}$ grupta yer alan kelimeler Arapçadan dilimize giren bāmiya kelimesiyle ilişkili olabilir. 
7- egrim/ eğlim/ ĕgrim/ eyrim/ klzıleğlim: Çekirge/Bursa; Balkusan-Ermenek/Kony (DS, V, 1685)

8- gafete/ galetel gavetel kafete:

Vefik Paşa, bu kelime grubunda yer alan kavata kelimesi için "patlıcan, acı domates, üzüm domates gibi maruf kırmızı meyve" (Vefik Paşa 2000 221). anlamlarını verir, ancak kelimenin menşei ile ilgili herhangi bir bilgi vermez.

\section{9- tombalak/ tonrak/ topalak/ dongurak/takalak}

$\mathrm{Bu}$ grupta yer alan adlandırmalar, Türkiye Türkçesi ağızlarındaki tombak "yuvarlak" kelimesinin fonetik hadiseler sonucu oluşan biçimlerdir. takalak: Buharı-Balaman-Fatsa/ Ordu (DS X, 3806) Maraş ağzında kullanılan takalak "yuvarlak bulgur köftesi" kelimesinden hareketle şekli bir adlandırma olabilir.

10- gırmızl/gırmuzu/ kırmızı

$\mathrm{Bu}$ grupta yer alan kelimeler, renk üzerinden yapılan adlandırmalardandır.

11- lalik/lolik/ lülük: Miçinkağ-Kemaliye / Erzincan; Ankara (DS IX, 3085) lolik kelimesi Ermenice'de domatesin karşılığıdır. (http://turkce-ermenice.cevirsozluk.com/ 10960238-domates)

12- thhl/tıhıl/tıkıl: Hekimhan/Malatya; Amasya; Erbaa/Tokat (DS IX, 3909-3910) Derleme Sözlüğü'nde $t \imath k \imath l$, "küçük parça, tane ve küçük topak" anlamlarının verildiği düşünürse bu grupta yer alan adlandırmalar bu şekil üzerinden olmalı.

13-balucak/bulacağı: Kelime Lazca'da domates anlamındadır. (http:lazuri.com/lazuri_ceviri/ index.php).

14- mısır/misir: Varyanl1/Maraş; Giresun ve çevresi (DS IX, 3189)

15- alaganta: Samsun (DS I, 187)

16- azak: Çarşamba ve köyleri, Kadamut/Samsun; Sonusa-Erbaa/Tokat (DS I, 434)

17- dibi kıllı: dibi+kıllı Akşehir/KONYA (DS IV, 1479)

18- gille: Görmel/Ermenek/Karaman; Gezende /Gülnar/Mersin (DS VI, 2078)

DS'de gille kelimesinin ilk anlamı "yuvarlak" biçiminde Zonguldak'ta kullanıldığ görülmektedir. Kelimenin ikinci anlamı "domates" anlamındadır. Muhtemelen ilk anlam olan yuvarlak biçim domates adlandırmasında rol oynamıştır.

19- herim: Erzurum (DS VII, 2348)

20- hülek: Antalya (DS VII, 2449)

21- kalmi: Bal1kesir, Kütahya (DS VIII, 2610)

22- kardoş: Karaçayır/ Tokat; Vazıldan / Divriği/Sivas (DS VIII, 2657)

23- kavanez: Bozkır, Hadim, Kayapınar / Konya (DS VIII, 2687)

24- klldir: Henya (Sivrihisar), Kalay (Bafra/Samsun) (DS VIII, 2795)

25- kokar: Derbent (Alaşehir / Manisa) (DS VIII, 2904)

Kelime kok- fiilinden domatesle ilgili bir adlandırmadır.

26- mırık: Bafra, Killik, Alaçam (Samsun) mırık kelimesinin "cıvık, bulanık su" anlamı Türkiye Türkçesi ağızlarında kullanılmaktadır. (DS IX, 3187) dolayısıyla bu adlandırma buradan gelebilir.

27- solik: Elazı̆g (DS X, 3661)

28- şamik: Siverek (Urfa), Diyarbekir, Adana (DS X, 3741)

30- tevris: Çivril (Denizli) (DS X, 3903)

31- yumru: Çankırı (DS XI, 4316) yumru kelimesinin "toparlak" anlamı Türkiye Türkçesi 
ağızlarından Merzifon, Amasya, Bayburt, Kars'ta da (DS XI, 4316) kullanılmaktadır. Dolayısıyla adlandırma şeklî olmalı.

32- zartlak: Antep (DS XI, 4351)

Derleme Sözlügü̈'nde yer almayan domatesle ilgili kelimeler şunlardır:

tomalta: Milas/Muğla, Sakarya; tamtes: Yazıhan/Malatya; sarı badılcan: Ayvancık/Sinop; sarı balcan: Ayvancık/Sinop; gırmızı badılcan: Kütahya; bulacă̆ı: Fındıkl1-Rize; bacan-ı sor: Batman; bacansor: Bismil/Diyarbakır; bacansorh: Ambar/Bismil/Diyarbakır.

Domates kelimesi haritası için bkz. Harita-1.

\section{Kedi}

Kedinin eski Mısırda günümüzden beş bin y1l öncesinde evcilleştirilmeye başlandığı, tahıl ambarlarının farelere karşı korumak için beslendiği, Eski Yunan'da orman tanrıçası Artemis'in kedi kılı̆̆ıyla dolaşması da kedinin Yunan kültüründe önemli bir yere sahip olduğunu göstermektedir. Ortaçă̆ Avrupa'sında ise kara kedilerin uğursuz sahiplerinin de cadı olarak değerlendirilmesi batıl inançların sosyal hayata yansımaları olarak değerlendirmek gerekir. İslam inancında kediyle ilgili olarak Hz. Peygamberin kedileri sevdiği, hatta müezze isimli bir kedisinin olduğu, kedilerle ilgili çeşitli hadislerin varlığ İslam kaynaklarınca zikredilmektedir (Ekiz 2004, 321, 322). Türklerde de kedi, temiz olmas1 sebebiyle evde beslenen ve değer verilen önemli hayvandır.

Türkçe'de kedi ile ilgili ilk adlandırmayı 11. yüzyılın büyük Türk dilcisi Kaşgarlı'nın eserinde çetük şeklinde görüyoruz. Kaşgarl, kedinin cinsiyetine göre de bir adlandırma yapmış ancak dişisi için ne söylendiğine dair bil bilgi vermemiş. çetük (Oğuzca) "kedi", kök çetük "erkek kedi" (Atalay 1991, I/388); küvük muş "erkek kedi" (Atalay 1991, III/165) Kaşgarlı, Çiğilce'de kedi için muş (Çiğilce) "kedi" kelimesinin kullanıldığını belirterek, kelimeyi cümle içerisinde kullanır (Atalay IV/415). muş oglı muyavu togar "kedi yavrusu miyavlarak doğar" (Atalay 1991, II/14). Eski Anadolu Türkçesi eserlerinden Süheyl ü Nevbahar ve Dede Korkut'ta da kedi kelimesi çetük şeklinde geçmiştir.

çetük kim ura pençesin așlana /eger diri kalur ise ușlana; gözetdi bir agaaç kaba vü yüce / çetük bigi țrmandı ol aǵaca; verrürlerdi itler çetüge selām /bir arada yérlerdi bile ța'ām (Cin 2012, 226/5, 270/8, 301/10) Hay ne oturursin, itüni avlatmayan, çetüğ̈̈ni mavlatmayan alplar başı Kazan oglancuğı ile serhoş olup yaturlar didi (Ergin 1989, 127/3). Ol mahallede anı ya it yiye/Ya çetük yiye vü hoş doydum diye (Komisyon 1996, II/872).

Harezm Türkçesi eserlerinde de kedi kelimesi için çetük ve möşük kelimelerinin kullanıldığ1 görülmüştür. Möşük tamdın tamga aşıp yörise yüz yıgaç yer yörir (Ata 1997, 23r/10). Bu etlerning guddalarını yıgıp bizim çetükke ıda bergil temiş erdi (Eckmann 1995, 312/8); çetük "kedi" (Yüce 1993, 27/8; 2134/4); çetik "kedi" (Battal 1997, 25). Çetük kim öz balasın togurup asrar/songı hem özi yir kör turfa bāzār (Hacieminoğlu 2000, 1920).

Kıpçak Türkçesi metinlerinde kedi için çetük ve bu kelimenin ses değişmesine uğramış biçimleri olan çetik, şetik, şetük kelimeleri kullanılmıştır. çetük "kedi" (Toparlı 2003, 80,109) işitkenin mını yok mı kaçan bolsa çetük âciz/urup pençe peleng közin çıkarur korkmayın ol dem (Karamanlıoğlu 1989, 36/18b/4).

Çağatay Türkçesi metinlerinde kedi kelimesi şu kelimelerle karşılanmıştır. müşük "dişi kediye derler" Bu hareket it müşük işidür (Kaçalin 2011, 773); bişik, mışık, müşek, möşük, feşek, kâte kelimeleri de Çağatay Türkçesinde kedi için adlandırılan kelimelerdir (Buhari 1298, 115...).

Osmanlı Türkçesi dönemi metinlerinde kedi ile ilgili olarak bulduğumuz kelimeleri Tarama 
Sözlüğü'nden aktaracağız. Pis, psik, püsük kelimeleri kedi için kullanılmış kelimelerdir (Komisyon 1996, 5/ 3198). Ankaralı Pir Mehmet Efendi, Tercaman adlı eserinde, El-fesfesetü [Ar.] kelimesini Pisiyi ve çetüğü mübalağa ile kovmak şeklinde açıklar (Komisyon 1996, 5/ 3198). Tiflisi'nin Arapça'dan Farsça'ya düzenlediği Kanun-ül-Edeb Tercümesi adlı eserde El-ehrar [Ar.] kelimesi, "Kediler ki Türkçe çetük ve kedence ve büsük derler" şeklinde açıklanmıştır (Komisyon 1996, 5/ 3198). Ankaralı Mustafa bin Mehmet'in Türkçe yazdığg Tebareke Tefsiri'de kedi kelimesi çetük şeklinde geçer. -Bir gece yaturdu, bir çetük pençesiyle urdu iki gözün çıkardı (Komisyon 1996, 5/ 3198). Amasyalı Deşişi Mehmet Efendi'nin Et-Tuhfetü's-Seniyye adlı eserine gorbe (Far.) için, kedi, çetük dahi söylendiğini belirtir (Komisyon 1996, II/ 872). Trobzonlu Aşık Mehmet bin Hafiz Ömer'in Menazırü'l-Avalim adlı eserinde sinnevr kelimesi, Farisî'de gorbe; Türkî'de çetik ve Moğoli'de migun denildiğini ifade eder (Komisyon 1996, II/ 873). Mustafa bin Mehmet bin Yusuf'un Camiü'-l Furs adlı eserinde gls (Far.) kelimesi ism-i savtır ki kediyi, yani çetüğü davet edip kigirmada istimal olunur. Bu diyarda pis pis derler. (Komisyon 1996, II/ 872). Aynı kelime, Hasan Bin Hüseyin İmamüddin'in Şamil-ül-Lüga adlı eserinde de gls (Far.) "pisi" demektir ki, çetügü davet etmekte istimal olunur. şeklinde açıklanır. (TS/II/ 872) Burhan-1 Katı'da, Pûşek ve puşik (Far.) kelimesi "kedi" anlamında olup Maveraü'n-nehr halkı kediye derler. Arabide sennevr denir. Zahiren pisik ta'biri püşsek musahhafidır." şeklinde açıklanmıştır (Öztürk \& Örs 2000, 613).

16. yüzy1l şairlerinden Me'āli'nin Mersiye-yi Gorbe adlı şiiri, Türk edebiyatında kedinin ölümü için yazılan nadir şiirlerden biridir (İsen 1993, 138-142).

görse bogardı baragı kovar idi çakalı / yolar idi eline girse keçinün sakalı

her ögünde yir idi keklik ile boz bakalı / N'edelüm āh pisi n'eyleyelüm āh pisi

Ey me'âli anun öldügini kim aglama / actyup hasret ile cānını kim daglama

cūş idüp kanlı yaşı seyl oluban çag̀lama / N'edelüm āh pisi n'eyleyelüm āh pisi

Son dönem Osmanlı Türkçesi sözlüklerinden Lehçe-i Osmani kedi için "her lisanda müstamel kıtta, klvırclk tüylü, sivri kuyruklu. Adi pisi, pisik, küt kuyruklu hirre, mavlar hayvan manasina kurbe" (Vefik Paşa 2000, 225). Kamus-1 Türki'de ise başlıca işi fare avlamak olan maruf hayvan-1 beyti, pisi (aslı pisik), klt, hirre (dişi kedi), gorbe (Sami 2010, 617, 974, 403). Toven ise, "Fare tutan maruf hayvan, pisi" (Toven 2004, 370). şeklinde açıklanmıştır. Türkçe Sözlükte ise, "Kedigillerden köpek dişleri iyi gelişmiş, kasları çevik ve kuvvetli, evcil küçük memeli hayvan, pisik (felis domesticus)" (Komisyon 2011, 1376) şeklinde açıklanır.

Günümüz Türklük dünyasından Güney-Batı Türk lehçelerinden Türkiye Türkçesi ve Gagauz Türkçesinde kedi (Doğru 1991). Azerbaycan Türkçesinde pişik (Altaylı 1994, 971). Türkmen Türkçesinde pişik (Tekin \& Ölmez et al. 1995, 531) kelimesi kullanılır. Güney-doğu Türk lehçelerinden Özbek möşük (Marufov 1981) Yeni Uygur Türkçesinde möşük (Necip 1995, 276); Kuzey-doğu Türk lehçelerinden Hakas Türkçesinde Rusça'dan geçtiğini düşünülen hoosha (Naskali G. \& Butanayev et al. 2007, 185). Altay Türkçesinde kiske, ve Moğolcadan Altay Türkçesine geçen miy: "kedi", erkek mıy "erkek kedi" kelimelerinin kullanıldığı görülür (Gürsoy \& Duranl1 1999 113, 134). Saha (Yakut) Türkçesinde kedi için kooska/kyoska; kyomka; kiça (Vasiliyev 1995, 151; Shcerbak 1961) kelimeleri kullanılmaktadır.

Kuzey-batı Türk lehçelerinden Kırgız mışık (Yudahin 1988), Tatar meçě, pěsi (Öner 2014) Kazak mısık (Koç \& Bayniyazov, et al. 2003). Başkurt bisey (Biişey, et al. 1993) KaraçayMalkar Türkçesinde ise kişdik kelimesi kullanılmaktadır. Kişdik balasın aşamaz "Kedi yavrusunu yemez"; kişdik çıçhanga aslan körünür "Kedi fareye aslan görünür" (Tavkul 2001, 165). Türkçenin uzak lehçelerinden Çuvaş Türkçesinde kedi için kuşak (Bayram 2007, 121) kelimesi kullanılmaktadır. 
Türkçenin komşu dillerinden kedi için Arapça'da bes/besse çokluk şekli bisas "kedi"; (Mutçalı 1995, 54) sinnevr çokluğu senanir (Mutçalı 1995, 411) kıtt: erkek kedi çoğulu kıtat, kıtata kitta (1995, Mutçalı 1995, 714) hir, çoğulu hirere; herir: "kedi" (Mutçalı 1995, 940). Modern Farsça'da kedi için gorbe (Muin 1386:3226) kelimesi kullanılmaktadır. Rusça'da kot "erkek kedi" (Ajegov, 2009, 300); koşka "dişi kedi" (Ajegov, 2009, 302). Moğolca'da kedi için mi(y) ve miguy kelimeleri kullanılmaktadır. (Lessing 2003, 841); Mançuca minuri,uyuri, kesike "kedi" Tunguzca'da koşka, kerke "kedi" kelimeleri kullanılmıştır. (Shcerbak 1961, 16-17) Bulgarca' da maca (Tietse 1999, 131) Yunanca'da ise kedi için gáta kelimesi kullanılmaktadır.

Derleme Sözlüğünde kedi kelimesinin taraması yapılırken kedi için özellikle cinsiyet, yaş ve diğer özelliklerine göre verilen adlandırmalar çalışmaya dahil edilmemiştir. kotak "erkek kedi"... (DS, VIII, 2935).

Türkiye Türkçesi ağızlarında tespit ettiğimiz kedinin diğer adlandırmalarını şöyle gruplandırabiliriz.

1. pısik /pış̧h /pışik/pisik /pissik /pisuk /pişiyh /pusuk /püssük /püsü/ mışık/mişik/pisigen /püsük/büssük/bisi/bişi/hisi/plsık/pisi/pisig/pisink/pisiyh/pist/piş/pişik/psi/pşi/pşik.

Söz konusu bu grup, Türkiye Türkçesi ağızlarında kedi kelimesinin diğer adları içerisinde en sık ve en geniş coğrafyaya dağılan biçimidir. Kelime Burhan-1 Katı'da Farsça puşek şeklinde gösterilmiştir. Ayrıca, Tarama Sözlüğü'nde kedi için Arapça-Türkçe ve Farsça-Türkçe sözlüklerde de Farsça olarak değerlendirilmiştir.

Grimm Kardeşler'e bakıldığında pisik kavramı, Kuzey Avrupa'dan da gelmiş olabilir. Zira İngilizce'de puss, Keltce'de pus, yay1larak Ulahlar'da pisicë, Kuzey İtalya'da micio, Tatarca'da mütsch şeklini almıştır (Grimm 1971, 11-282).

2. maş /meci /maçi/meçük.

$\mathrm{Bu}$ grupta yer alan kedi adlandırmaları, $b-, m-, p-, S^{-}, c ̧$ - ses değişmelerinin neticesinde ortaya çıkmış varyantlardır. Türkçenin tarihi metinlerinden Harezm ve Çağatay Türkçesinde kedi için kullanılan şu adlandırmalar möşük, müşek, bişik, müşük bu durumu tanıklamaktadır.

Tietse, Türkiye Türkçesinde maçi (Tekirdağ); maş (Giresun, Sivas) kelimelerini göz önünde bulundurarak bu kelimeleri Bulgarca maca "kedi" kelimesine bağlar. Tietse, söz konusu örneklerden hareketle bu kelimenin versiyonlarının dağılımının bu kelimelerin Balkan dillerinden ödünçlendiğini göstermektedir şeklinde açıklar (Tietse, 1999, 131). Tietse, Balkanlardan yeni yerleşim bölgelerine geri dönen Türklerin birçok kelimeyi beraberinde getirdikleri düşünür (Tietse, 1999, 11/3).

\section{3. gedi/kedik/katu/kit/kitik.}

Kedi kelimesini ilk olarak 17. yüzyıl Osmanlı Türkçesinin söz varlığında görüyoruz. kedi "çetük, hirr" (Tulum, 2011, 1024) Bu grupta yer alan kelimeler, muhtemelen bugün kullandığımız kedi kelimesin fonetik hadiseler sonucu kullanılan biçimleridir. Schrader, kedi kelimesiyle ilgili olarak Orta Latince'de (MS 600"lü yıllar) de evcilleşmiş kedi anlamında cattus, catta kelimeleri olmasına rağmen Avrupa'ya yayılmış olan Kedi'nin şekillerinin yüksek Almanca'daki chazza, chataro ve Keltce'deki cat, caz'dan geldiğini savunur. (Schrader 1907, 163 166). Bu şekliyle de Avrupa'da yaygındır. Fransızca chat, İspanyolca gato, İtalyanca gatto, Fince katti, Gürcüce kati, Türkçe kedi, Ermenice citte'dir (Grimm 1971, 11-281). Gülensoy da, Eski Türkçe'deki çetük kelimesinin Türkiye Türkesi ağızlarında da görülen $c ̧$ - $>k$ - değişmesine paralel alarak ses değişmesine uğrayarak çetük $>k e d \ddot{u}+k$ biçimini aldığını söyler (Gülensoy 2007, 492). 
4. manı/manik/manuk: Adana (DS, IX, 3122).

Clauson, Şhcerbak'ın, manu kelimesinin Tuva Türkçesinde "vahşi kedi" anlamında kullanıldığını belirtip, Türkçe molun "vahşi kedi" kelimesinde manul'dan "evcil kedi" dönüşmüş olabileceğini söyler (Clauson, 1972, 767).

5. hiştik/kiştik/kişdik.

$\mathrm{Bu}$ grupta yer alan kedi isminin Karaçay-Malkar Türkçesindeki, kişdik kelimesiyle aynı olduğunu görüyoruz.

\section{6. bisden /bisten /pistan:}

Bu grupta yer alan kedi adlandırması pis, pisi, bis "kedi" gibi adlandırmaların üzerine den/ten eki getirilerek yapılmıştır. Türkiye Türkçesi ağızlarında kediyi çağırmak için bîsdēn, bîstēn şeklindeki kullanımlar bilinmektedir. Söz konusu adlandırma, bu sesleneme biçiminden ortaya çıkmış olabilir.

\section{7. mırmırık: Mustafa Kemal Paşa/Bursa}

Mırmırık adlandırması, kedinin uyurken çıkardığı "mırrı, mırı" gibi seslere istinaden yapılan bir adlandırma olabilir.

\section{8. tekir: Uşak}

Tekir kelimesi, renk adlandırmasından kedi anlamında kullanılmaya başlanan bir addır. Son dönem Osmanlı Türkçesi sözlüklerinde bu durum görülmektedir. Vefik Paşa, tekir kelimesini "benek, benekli, esmer, bir nev kaplan, tekir kedi "şeklinde açıklarken (Vefik Paşa 2000, 375) Ş. Sami "siyah benek yahut çizgilerle karışık kül renginde: tekir kedi, kaplan" (Sami 1316, 432) şeklinde bir açıklama yapar. Anlaşılan o ki, renk üzerinden kediye verilen ad, daha sonra genelleşerek kedi için kullanılmaya başlanmıştır ( Tekir ördeği, tekir balı̆̆t).

9. bavuk: Arapkir/Malatya (DS, II, 574)

Kelime Türkiye Türkçesi ağızlarında sadece bir yerde geçmektedir. Bavuk kelimesinin, Türkiye Türkçesi ağızlarında geçen "sert sert öksürmek", "kızarak deli gibi söylenmek" gibi anlamlarda kullanılan pavkır-; pavkur-; pavla- kelimeleriyle ilişkili olabilir.

10. gebis: Uğurlu-Ermenek/Konya (DS, VI, 1957)

Gebis kelimesi bölge ağzında gelbisi/gelpisi şeklinde olup kedi çă̆ırmak için kullanılır. Kelime ağızda kullanılırken ses düşmesine uğrayarak gebis biçimine dönmüştür.

11. sımcak: Çakalli/Adana (DS, X, 3608)

12. kere: Maçka /Trabzon

Kere kelimesi, Arapça hir, çoğulu hirere, herir kelimesinin Türkçede bozularak kullanılan biçimi olabilir.

\section{3. pencik:}

Pencik kelimesinin Farsça'dan dilimize geçen pençe "yırtıcı hayvanların ön ayaklarının parmaklarıyla tırnakları" kelimesiyle ilgili olmalıdır.

Derleme Sözlüğü'nde yer almayan kediyle ilgili kelimeler şunlardır: kere: Maçka/Trabzon; katu: Fındıklı/Pazar/Rize; kit: Kars; kitik: Şırnak; gedi: Trabzon; tekir: Uşak; pencik: Amasra/Bartın

Kedi kelimesi haritası için bkz. Harita-2. 


\section{Sonuc}

Domates, patates ve kedi kelimelerinin harita üzerindeki dağılımı gösteriyor ki, Türkiye Türkçesi ağızları arasında dinamik bir etkileşim vardır. Bu dinamizme sebep olan etkenlerin öne çıkanları, komşu ülkelerin dilleri ve göçlerdir. Komşu dillerden ve göçler sonucunda ödünçlenen kelimeler, Türkiye Türkçesi ağızlarında istisnaları olmakla birlikte, genel olarak ses ve şekil değişikliklerine uğrayarak çeşitlenirler. Haritada yaygın olmayan adlandırmalar ise, genelde söz konusu nesnelerin fiziksel özelliklerine gönderme yapan adlandırmalardır. Kavramların adlandırılmasındaki çeşitliliğin fazlalı̆̆ı, haritada dikkat çekse de, bazı adlandırmaların diğerlerine göre daha yaygın olduğu görülmektedir. 


\section{KAYNAKÇA}

Ajegov S. İ.- Şvedova H. Yu. (2009) Tolkoviy Slovar Ruskogo Yazıka. Moskva 2009.

Akar A. (2013). Muğla ve Yöresi Ağızlarl: Gramer-Metin-Sözlük. Ankara 2013.

Altaylı S. (1994). Azerbaycan Türkçesi Sözlü̆̈̈̈ I-II. İstanbul 1994.

Ata A. (1997). Kısasü'l-Enbiya I, Giriş-Metin-Tipkıbasım. Ankara 1997.

Atalay B. (1992). Divanü Lugati't-Türk Tercümesi I, II, III, IV. Ankara 1992.

Barth E. (1972). Deutscher Wortatlas 1939-1971: Eine Bibliographie. Germanistische Linguistik, 72/3, 125-156.

Başkan Ö. (1970) "Türkiye Köy Adları Üzerine Bir Deneme", Türk Dili Araştırmaları Yıllığı Belleten, Ankara (1970) 237-251.

Battal A. (1997). İbn-i Mühenna Lügatı. Ankara 1997.

Bayram B. (2007). Çuvaş Türkçesi-Türkiye Türkçesi Sözlük. Konya 2007.

Biişev E. G. \& Bikbulatov N.V., vd. (1993). Başkort Télénén Hüzlégé I-II, Moskva 1993

Buran A. (2009). Doğu ve Güneydoğu Anadolu'nun Dil Atlası. İstanbul 2009.

Buhari Ş. S. (1298) Lügat-ı Çağatayi ve Türki-yi Osmani. İstanbul 1298.

Caferoğlu A. (1960) "Atlente Linguistico Mediterraneo", Türk Dili ve Edebiyatı Dergisi, İstanbul, Cilt 11. (1960) 11-18.

Caferoğlu A. (1960) "Türkiye Balık Adları", Türki Dili ve Edebiyatı Dergisi, İstanbul, Cilt 10 (1960) 111-132.

Caferoğlu, A. (1994). Anadolu Dialektolojisi Üzerine Malzeme: Oyunlar, Tekerlemeler, Yaniltmaçlar ve Oyun Istılahları. 1. Cilt Ankara 1994.

Cin A. (2012). Süheyl ü Nevbahar. Konya 2012.

Clauson G. (1972). An Etymological Dictionary of Pre-Thirteenth-Century Turkish. Oxford 1972.

Doğru A. \& Kaynak İ. (1991). Gagauz Türkçesinin Sözlügü. Ankara 1991.

Eckmann J. (1995) Nehcü'l-Feradis, I Metin (Yayımlayanlar: Tezcan S. \& Zülfikar H.) Ankara 1995.

Ekiz M. (2004) "İslam Minyatür Sanatında Kedi Figürüne Genel Bir Bakış", Cumhuriyetimizin 80. Kuruluş Yıldönümü Anı Kitabı. Ankara 2004.

Ercilasun A. B. (1983). Kars İli Ă̆gzlarl, Ses Bilgisi. Ankara 1983.

Ergin M. (1989) Dede Korkut Kitabı. Ankara 1989.

Gemalmaz E. (1995). Erzurum İli Ağızları İnceleme-Metinler-Sözlük ve Dizinler. 11l. Cilt Ankara 1995.

Grimm, J., \& Grimm, W. (1971). Deutsches Wörterbuch Von Jacob Grimm und Wilhelm Grimm. Leipzig 1971.

Gülensoy T. (2007). Türkiye Türkçesindeki Sözcüklerin Köken Bilgisi Sözlü̈̆̈̈. Ankara 2007.

Gülseren C. (2000). (Malatya İli Ağızları İnceleme-Metinler-Sözlük ve Dizinler). Ankara 2000.

Hacıeminoğlu N. (2000) Kutb'un Hüsrev ü Şirin'i ve Dil Hususiyetleri. Ankara 2000.

İsen M. (1993). Acryı Bal Eylemek, Türk Edebiyatında Mersiye. Ankara 1993.

Kaçalin M. (2011). Nevayi'nin Sözleri ve Çağatayca Tanıklar. Ankara.

Kanar M. (1998) Farsça-Türkçe Sözlük İstanbul 1998.

Karahan L. (1996). Anadolu Ağızlarınin Sinıflandırllması. Ankara 1996.

Karahan L. (2013) "Gramatikal Ölçütlerle Belirlenen Türkiye Türkçesi Ağız Gruplarında Leksik Verilerin Anlamlılı̆̆ Üzerine Bir Araştırma" Diyalektoloji, Sayı 7 (1996) 1-12.

Karamanlıŏlu A. F. (1989) Gülistan Tercümesi. Ankara 1989.

Koç Kenan \& Aybek B., Başkapan V. (2003). Kazak Türkçesi-Türkiye Türkçesi Sözlügü. Ankara 2003.

Komisyon (1993). Derleme Sözlüğ̈̈, Ankara 1993.

Komisyon (1996). Tarama Sözlüğ̈̈, Ankara 1995.

Komisyon (2011). Türkçe Sözlük, Ankara 2011.

Kurban İ. (1985). Yeni Uygur Türkçesi Sözlüğü. Ankara 1985.

Lessing D. F. (2003). Moğolca-Türkçe Sözlük (Çev: Günay Karaağaç) Ankara 2003.

Marufov Z.M. et al. (1981). Özbek Tiliniy İzahl Lügati, I.,II., Moskova 1981. 
Mitzka W. (1938). "Der deutsche Wortatlas", Zeitschrift für Mundartforschung, 1/14, 40-55.

Mitzka W. (1939). "Der Fragebogen zum Deutschen Wortatlas" Zeitschrift für Mundartforschung, 1(15), (1939) 105-111.

Mitzka W. (1952). Handbuch zum deutschen Sprachatlas. Marburg 1952.

Muin M. (1386) Ferheng-i Farisi.Tehran 1386.

Mutçalı S. (1995) Arapça-Türkçe Sözlük. İstanbul 1995.

Naskali G. E. \& Butanayev V., İsina A., et al. (2007). Hakasça-Türkçe Sözlük, Ankara.

Naskali G. E. \& Duranlı M. (1999). Altayca-Türkçe Sözlük, Ankara.

Niebaum, H., \& Macha, J. (2014). Einführung in die Dialektologie des Deutschen. Berlin 2014.

Öztürk M. \& Örs D. (2000) Burhan-ı Katı. Ankara 2000.

Öztürk, J. (2009). Hatay Ağzl: Inceleme-Metin-Sözlük. Adana 2009.

Öztürk, Ö. (2005). Karadeniz: Ansiklopedik Sözlük. 11. Cilt. İstanbul 2005.

Samanc1, Ö (2008). İmparatorluğun Son Döneminde İstanbul ve Osmanlı Saray Mutfak Kültürü. İstanbul 2008.

Sami Ş. (1316). Kamus-ı Türkî, İstanbul 1316.

Schrader O. (1907). "Sprachvergleichung und Urgeschichte", Linguistisch-historische Beiträge zur Erforschung des indogermanischen Altertums. Jena 1907.

Sçerbak, A.M. (1961) "Names of domesticated and wild animals in Turkic languages" Historical development of lexicon in Turkic languages (1961) 82-172

Tavkul U. (2001). Karaçay-Malkar Atasözleri. Ankara 2001.

T. Talât. Ölmez M., Ceylan E., Ölmez Z., \& Eker S., (1995). Türkmence-Türkçe Sözlük, Ankara 1995.

Tietze A. (1999). Wörterbuch der griechischen, slavischen, arabischen und persischen Lehnwörter im Anatolischen Türkisch: Anadolu Türkçesindeki Yunanca, İslavca, Arapça ve Farsça Ödünçlemeler Sözlüğ̈̈. İstanbul 1999.

Toparl, R. (2003). Ed-durretü'l-Mudiye Fi'l Lügati't-Türkiyye. Ankara 2003.

Vasiliev Y. (1995). Türkçe-Sahaca (Yakutça) Sözlük. Ankara 1995.

Vefik Paşa Ahmet, (2000). Lehçe-i Osmanî, (Haz: Recep Toparlı) Ankara 2000.

Wiegand, H. E., \& Harras, G. (1971). "Deutscher Wortatlas: Zur wissenschaftshistorischen Einordnung und linguistischen Beurteilung des Deutschen Wortatlas" Germanistische Linguistik, 71/1-2 (1971) $1-204$.

Yıldırım F. (2006). Adana ve Osmaniye İlleri Ağızları: Metinler-Sözlük-Dizinler. 1l. Cilt Ankara 2006.

Yudahin, K.K. (1988). Kırgız Sözlüğ̈̈, (Çev: Abdullah Taymas) Ankara 1998.

Yüce N. (1993) Mukaddaimetü'l-Edeb. Ankara 1993. 
Haritalar için bir sonraki sayfaya geçiniz. 


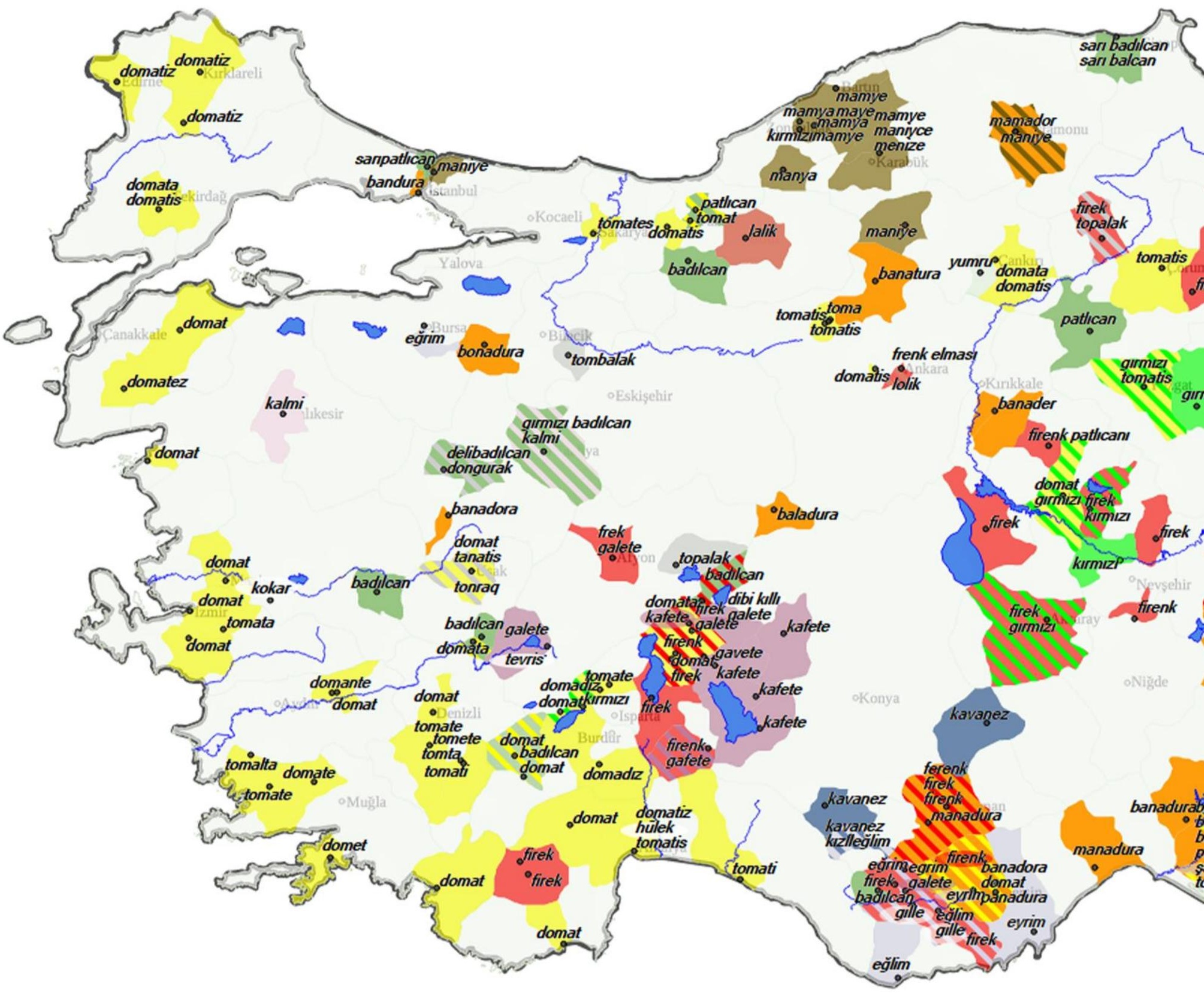

Harita 1. Türkiye Türkçesi Ağıları Haritası "Domates". 


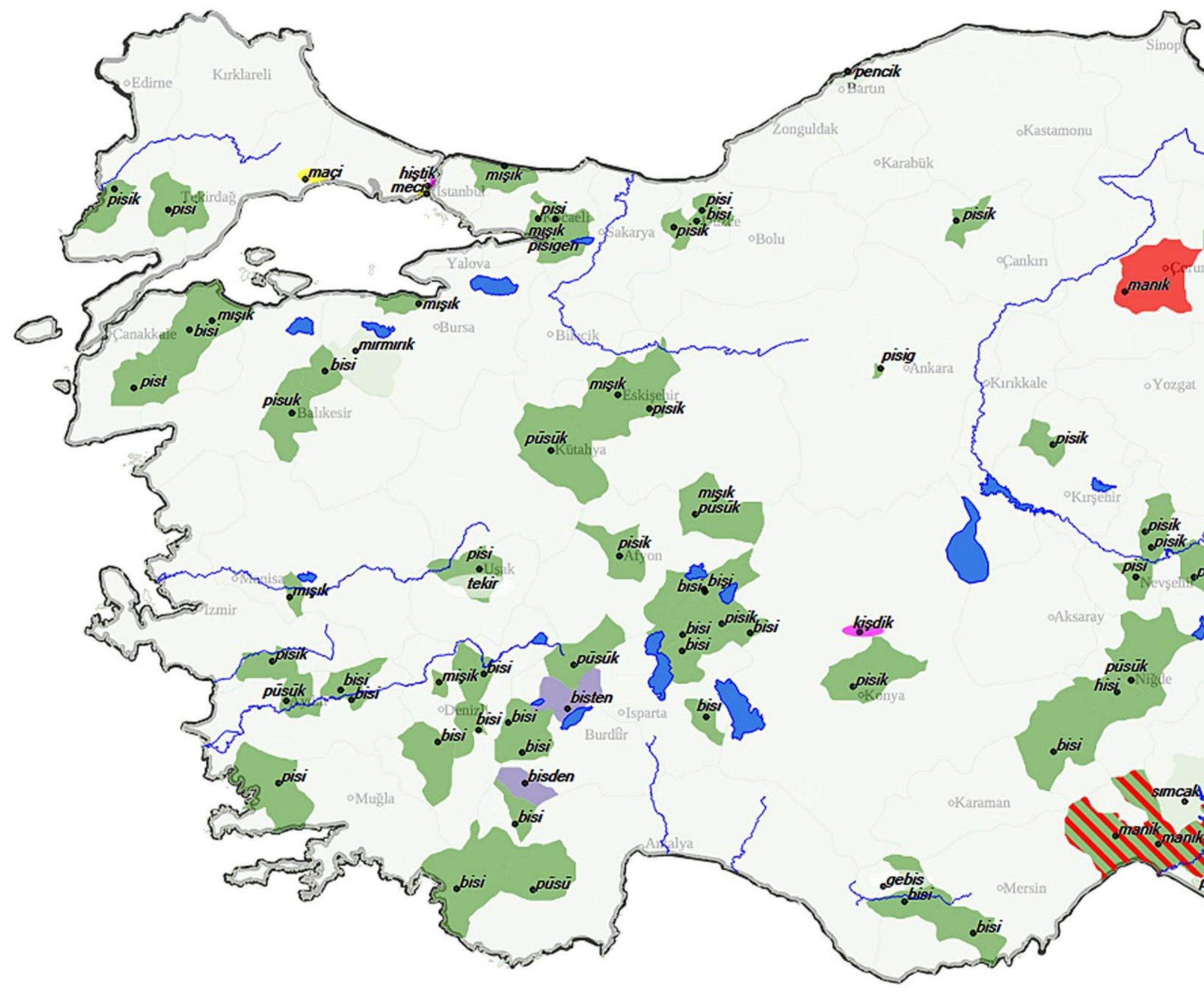

Harita 2. Türkiye Türkçesi Ağızları Haritası "Kedi". 


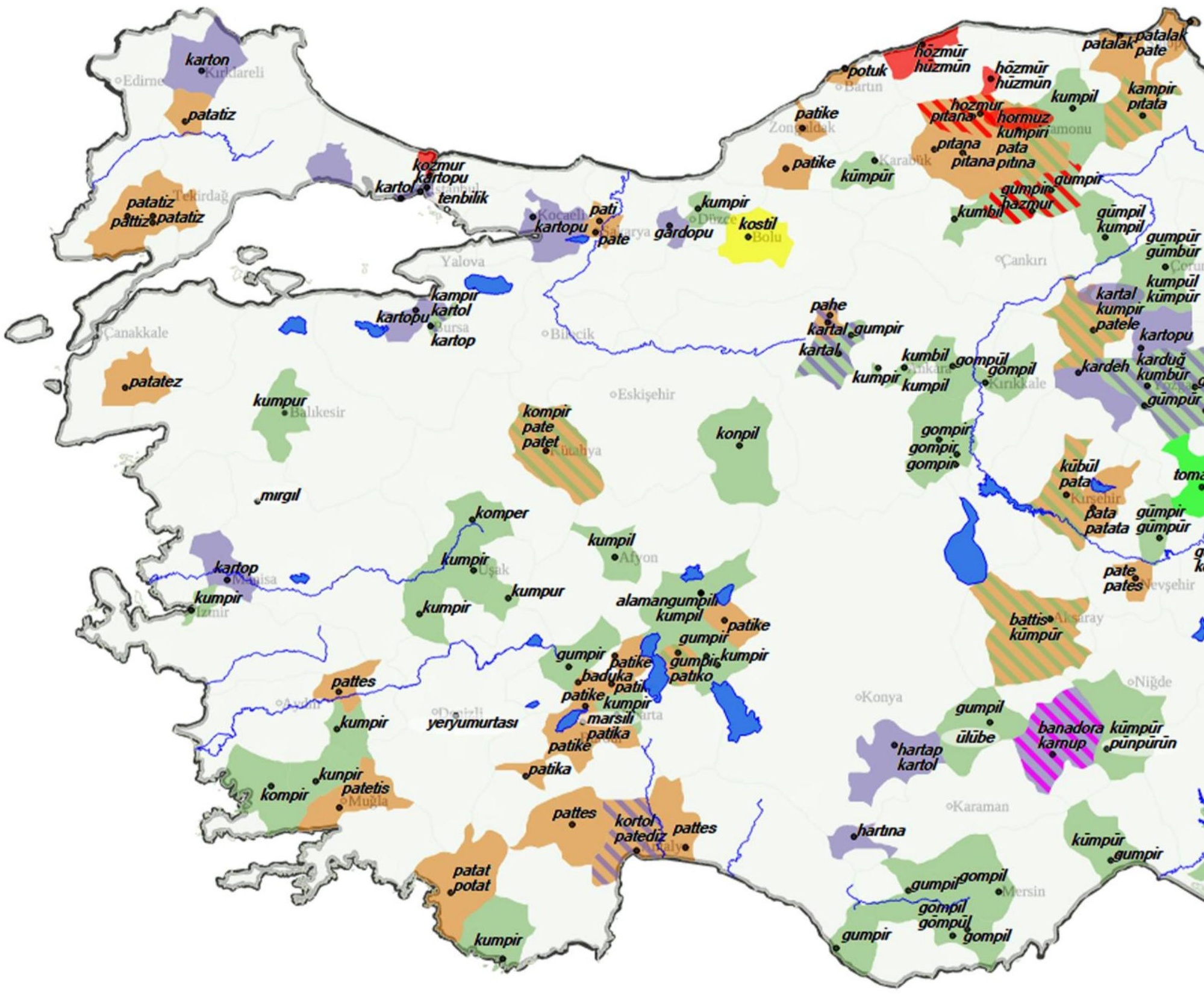

Harita 3. Türkiye Türkçesi Ağızları Haritası "Patates". 
